\title{
Reproductive Dysfunction in Female Offspring after Prenatal Exposure to Phenobarbital: Critical Period of Action
}

\author{
CHHANDA GUPTA AND SUMNER J. YAFFE ${ }^{(27)}$ \\ Departments of Pediatrics and Pharmacology, University of Pennsylvania, School of Medicine and The Children's \\ Hospital of Philadelphia, Philadelphia, Pennsylvania, USA
}

\begin{abstract}
Summary
Phenobartital (PB) (40 mg/kg/day) was administered to pregnant rats at 12 to 20,14 to 20 , and 17 to 20 days of gestation and female offspring were tested for the onset of puberty, estrous cycle pattern, and fertility. Another group of rats received PB $(20 \mathrm{mg} /$ $\mathrm{kg} /$ day) during the neonatal period (1 to 8 days). PB administration during both the pre- and postnatal periods resulted in a significant delay in the onset of puberty (control: $34.6 \pm 1.2$ days, PB: $37.5 \pm 1.2$ days), disorders of estrous cycle (control: normal cycles $91 \%$, PB: normal cycles $40 \%$ ), and infertility (control: $100 \%$ fertile PB: $50 \%$ fertile). Associated with these effects, we observed high levels of estrogen in plasma (control: $58.5 \pm 12.2 \mathrm{pg} / \mathrm{ml}, \mathrm{PB}$ : $155.2 \pm 25.1 \mathrm{pg} / \mathrm{ml}$ ) and increased estrogen receptors in the uterus (control: $0.136 \pm 0.026$ pmole/mg protein, PB: $0.242 \pm 0.031$ $\mathrm{pmole} / \mathrm{mg}$ protein. This study shows that $\mathbf{P B}$ administration only during the period of neuroendocrine differentiation ( 17 to 20 days of pregnancy and 1 to 8 postnatal days) is capable of producing all of the adverse effects of $\mathrm{PB}$, indicating that its action is upon neuroendocrine development.
\end{abstract}

\section{Speculation}

Since phenobarbital (PB) administration during 17 to 20 days of pregnancy is capable of producing reproductive disorders in the offspring, the results suggest that PB interferes with neuroendocrine differentiation. The mechanism of action of $\mathrm{PB}$, however, has not been delineated. Neuroendocrine differentiation is mediated by gonadotropin, present during the neonatal period. PB may act at this site by interfering with gonadotrophin release or action. Support for this hypothesis is derived from the observation that PB can inhibit gonadotrophin secretion in the adult rat.

Phenobarbital (PB), a psychotropic agent widely used during pregnancy, has been shown to modify reproductive development in different species $(3,6,19)$. Clemens et al. (3) demonstrated that neonatal administration of $\mathrm{PB}$ produces feminine sexual behavior in male hamsters. Nishizuka (19) showed that neonatal administration of PB is capable of neutralizing the defects in reproductive function resulting from neonatal androgen administration. We have demonstrated that PB administered to pregnant rats results in reproductive dysfunction in both male (13) and female offspring (12).

The results of our studies were based upon PB administration from day 12 to 19 of pregnancy. This time frame includes all periods of sexual differentiation $(2,5,20,24)$. These are (1) the period of gonadal differentiation, when the testes start producing testosterone and the ovary synthesizes estrogen, (2) the period of somatic sexual differentiation when the seminal vesicle, prostate, Wolffian duct develop in the male and when the vagina develops (Wolffian duct regresses) in the female, and (3) the period of later somatic sexual differentiation when the development of external genitalia is initiated. At this time, the neuroendocrine axis also starts developing. In the rat, $(2,7,14,15,21,26)$ the chronologic sequence of these stages of sexual differentiation takes place at 12 to 14,14 to 16 , and 17 to 20 days of gestation, respectively. In order to understand the mechanism of PB action, it is important to delineate the precise time of action within the overall period of sexual differentiation. Therefore, this study was planned to determine which of the above mentioned developmental systems was affected, by exposing the offspring to PB during the different periods of sexual differentiation. In addition, the effect of $P B$ on the neonatal rat was studied to investigate its effect upon late neuroendocrine development, which takes place during the first week of postnatal life.

\section{MATERIALS AND METHODS}

\section{ANIMALS AND TREATMENT}

Since PB has a long half-life [approximately 5 days $(12,17$, $25)$ ], the experimental protocol was designed to take this into consideration. This was accomplished by determining the period(s) of sexual differentiation, not affected by PB and then identifying the period, which is affected, using overlapping periods of drug administration and the process of elimination. PB was administered at either 12 to 20,14 to 20 , or 17 to 20 days of gestation or during postnatal days 1 to 8 . The mothers received 40 $\mathrm{mg} / \mathrm{kg} /$ day, once a day subcutaneously. Newborns received 20 $\mathrm{mg} / \mathrm{kg} /$ day via the same route. Control animals received vehicle only. The number of offspring in each litter was adjusted to eight to ten of equal sexes at birth. The rats were maintained in a controlled temperature room with a 12-hr dark cycle. Pups were weaned at 21 days of age. Food and water were supplied ad libitum throughout the experiment. The animals were weighed once every week. Only the female offspring were analyzed. Timed pregnant Sprague-Dawley rats were obtained from Charles River Laboratories.

\section{BIOLOGIC FUNCTION}

The onset of puberty was determined from the time of vaginal opening and the appearance of the first estrus smear. The estrous cycle was examined when the rats were about 60 days of age with a smear prepared every day for 12 consecutive days. Fertility was determined by mating at 80 to 90 days of age with normal males over a period of 5 to 15 days until there was evidence of successful mating, as determined by the presence of spermatozoa in the vagina. The presence of implantation sites was verified by cesarean section. A group of animals which had all other biologic functions examined except for fertility was killed at 3 months of age when they were in estrus and blood was collected for estrogen estimation. The uteri of these animals were used to determine estrogen receptor concentration and affinity. 


\section{ESTRADIOL ASSAY}

Estradiol-17 $\beta$ was assayed in plasma according to the radioimmunoassay procedure of Korenman et al. (16) using the antiserum from Dr. G. D. Niswender. A 1 to $2 \mathrm{ml}$ plasma sample was required for the assay because of the low plasma concentrations. Approximately $1000 \mathrm{CPM}$ tritiated estradiol were added before extraction with 10 volumes of diethyl ether. The solvent layer was evaporated to dryness and dissolved in $0.1 \mathrm{ml}$ of isoctane:benzene: methanol (62:20:18). Estradiol-17 $\beta$ was purified from the other steroids by LH-20 column chromatography. The estradiol fraction was collected and evaporated to dryness and then redissolved in $0.3 \mathrm{ml}$ ethanol; $0.1 \mathrm{ml}$ was taken for recovery check and $0.1 \mathrm{ml}$ was used for the assay.

Buffer, estradiol (7000 to $8000 \mathrm{CPM}$ of $1,2,6,7 \cdot{ }^{3} \mathrm{H}$ estradiol), and antiserum $(25 \mu \mathrm{l}$ of $1: 8000 \mathrm{CPM})$ were added in a total volume of $0.3 \mathrm{ml}$ and incubated at $25^{\circ} \mathrm{C}$ for $1 \mathrm{hr}$. For the standard curve determination, a series of tubes containing $0.1 \mathrm{ml}$ of estradiol solutions $(0.08$ to $2.5 \mathrm{ng} / \mathrm{ml})$ were made and incubated as described for unknown samples. At the end of incubation, the free steroid was removed with $0.5 \mathrm{ml}$ of dextran coated charcoal ( $0.325 \%$ Norit $A$ and $0.025 \%$ dextran T-70 in buffer). The supernatant was then counted.

\section{ESTRADIOL RECEPTOR ASSAY}

Uterine receptor concentration was determined by the method of Gupta and Bloch (9) with some modification. Uteri were homogenized 1:8 in buffer (0.02 $\mathrm{M}$ tris, $0.005 \mathrm{M}$ EDTA, pH7.4). The $100,000 \times g$ supernatant fractions from these tissues were incubated with $30 \mathrm{nM} 6,7-{ }^{3} \mathrm{H}$ estradiol- $17 \beta$ with or without 100 fold excess of unlabeled estradiol for $2 \mathrm{hr}$ at $4^{\circ} \mathrm{C}$. This assay condition was found to give maximum binding at that tissue concentration. Free estradiol was removed by treating with dextran-coated charcoal solution, containing $0.05 \%$ dextran and centrifuged immediately at $1500 \times g$ for $15 \mathrm{~min}$. The supernatant was counted and protein concentration was determined. Receptor concentration per $\mathrm{mg}$ protein was calculated by dividing the specific binding at $30 \mathrm{nM}{ }^{3} \mathrm{H}$-estradiol by protein concentration present in the supernatant.

\section{STATISTICAL ANALYSIS}

The results were analyzed according to the usual methods of Student's $t$ test. The functional parameters were evaluated by $\chi^{2}-$ analysis.

\section{RESULTS}

The dose of PB used in this study did not produce any observable effects in the mothers. Both control and PB-treated mothers delivered at 21 to 22 days of gestation. At birth, the offspring from the PB-treated mothers showed no gross anatomic malformations. Litter size and birth weights were similar to those of control offspring. PB injected in the newborn rat produced sleep for a short time. Animals were alert within 2 to $3 \mathrm{hr}$ and appeared to nurse similarly to controls. Until weaning ( 21 days of age), both pre- and postnatally PB exposed offspring were similar in body weight to control offspring. However, the PB exposed offspring had significantly lower weights from 20 to 50 days of age (the most rapid period of postnatal growth). After this age, differences in body weight were not significant.

The onset of puberty was determined from the day of vaginal opening and the first appearance of estrus smear. PB administration during neuroendocrine development, namely, 17 to 20 days of pregnancy and 1 to 8 days postnatally, produced a similar delay as that produced by PB administration at 12 to 20 or 14 to 20 days of gestation (Table 1, $P<0.05$ ). Estrous cycle analysis (Table 1) also showed that $P B$ administration during the period of neuroendocrine differentiation (17 to 20 days of pregnancy and 1 to 8 postnatal days) alone was as capable of producing significant disorders of estrous cycle $(P<0.05)$ as that found after PB administration during the whole period of sexual differentiation
(12 to 20 and 14 to 20 days of gestation). These results suggest that PB may interfere with neuroendocrine differentiation without affecting the differentiation of the gonadal and ductal systems. A large percentage of animals (15 to $30 \%$ ) from the different treatment groups exhibited estrus vaginal smears for 70 to $80 \%$ of the cycle (persistent estrous). A small percentage of animals (4 to 12\%) even showed constant estrous cycle, without any evidence of diestrus smear during the time of examination (at least 12 consecutive days). In the control group, very few of the animals (10\%) had persistent or constant estrous cycle. The number of animals having a normal cycle in the 1 to 8-day postnatal group is higher compared to the prenatal PB group, suggesting that this period of late neuroendocrine differentiation is less sensitive to $P B$ action.

The results of fertility analysis are presented in Table 2. Again, fertility was significantly reduced in PB exposed females at all different treatment times. The animals having persistent estrous cycle were infertile. However, the incidence of infertility in both groups became insignificant (data not shown) when the animals were mated over a longer period of time (15 days). This resulted from the ability of the rats with persistent estrus to conceive when they were allowed to remain with a normal male for a longer period of time, but animals with constant estrus never conceived. Resorption was also seen frequently in the untreated animals irrespective of vaginal cyclicity (Table 2 ).

In order to investigate further the underlying cause of the reproductive failure of the $\mathrm{PB}$ exposed offspring, we assayed estrogen concentrations in plasma (Table 3). A significant increase in plasma concentration of estrogen was found in all groups of treated animals. However, the increase in estrogen concentration was more pronounced in the postnatally PB exposed offspring compared to the prenatally PB exposed offspring. In addition, we found a significant increase in estrogen receptor (cytoplasmic) concentration in the uterus of all groups of PB exposed offspring.

\section{DISCUSSION}

During the last half of pregnancy, a rapid differentiation of various sexual characteristics takes place. In the rat exhaustive studies have been undertaken to define the critical periods for the development of the specific sexual characteristics $(1,14,20,21$, 25). PB may interfere with the differentiation of one or more of these systems. In the present study we have attempted to determine the precise temporal site of action of the drug.

The long half-life of phenobarbital has made this task difficult. As a result, we could not determine its time of action simply by administering the drug at different critical periods of development. Therefore, an alternative approach was adopted by administering the drug at the end of different critical periods of development and conclusions concerning its time of action have been drawn by eliminating the periods that were not affected or were not necessary to produce PB-effects.

The results of our study show that PB exposure only during the period of neuroendocrine development (17 to 20 days) is capable of producing all PB effects, indicating that its action occurs at this time. The results further suggest that PB does not need to be present during earlier periods of sexual differentiation to produce its effects, indicating that PB does not interfere with gonadal or ductal differentiation.

The fact that PB effects on reproductive function can occur from postnatal administration (when the ductal and gonadal stages of sexual development have been completed) lends further support that its action is upon neuroendocrine differentiation.

The dosage of PB used in this study is moderately high. It is possible, therefore, that the effects observed in the offspring are due to its secondary effects such as hypoxia or change in food intake. However, PB at $40 \mathrm{mg} / \mathrm{kg} /$ day had no effect upon normal activity, food intake, or body weight gain of the mother. The offspring appeared quite normal (body weight at birth and body weight gain until puberty similar to controls). Activity and reflexes were also normal. The effects on the offspring appeared later in life in the absence of PB. Therefore, it is unlikely that the effects 
Table 1. Effect of $P B$ administration during pre- and postnatal period on onset of puberty and estrous cycle

\begin{tabular}{|c|c|c|c|c|c|}
\hline & $\begin{array}{c}\text { Control } \\
(16)^{1}\end{array}$ & \multicolumn{4}{|c|}{ PB at: } \\
\hline \multicolumn{6}{|l|}{ Onset of puberty } \\
\hline Vaginal opening (day) & $34.6 \pm 1.2$ & $38.4 \pm 1.11^{2}$ & $37.2 \pm 1.14^{2}$ & $37.5 \pm 1.20^{2}$ & $36.4 \pm 1.30^{2}$ \\
\hline First estrus smear (day) & $34.9 \pm 1.7$ & $39.1 \pm 1.23^{2}$ & $39.5 \pm 2.20^{2}$ & $37.6 \pm 1.10^{2}$ & $37.8 \pm 1.21^{2}$ \\
\hline Normal $^{3}$ & 91 & $47^{2}$ & $52^{2}$ & $46^{2}$ & $70^{2}$ \\
\hline Irregular & 9 & 30 & 22 & 5 & 5 \\
\hline Persistent estrous & 0 & 15 & 22 & 36 & 25 \\
\hline Constant estrous & 0 & 8 & 4 & 12 & 0 \\
\hline
\end{tabular}

'The number in the parentheses indicates the number of animals.

${ }^{2} P<0.05$ by Student's $t$ test or $\chi^{2}$-analysis with Yates correction.

${ }^{3}$ Normal cycle refers to 2 days of estrus, followed by 2 to 3 days of diestrus. Animals with persistent estrus exhibited estrus smear during 70 to $80 \%$ of the cycle. Animals with constant estrus showed no diestrus smear at the time of examination.

Table 2. Effect of $P B$ administration during pre-and postnatal periods upon fertility.

\begin{tabular}{lccc}
\hline \multicolumn{1}{c}{ Treatment } & $\begin{array}{c}\text { Fertile }^{1}(\% \text { of ani- } \\
\text { mals) }\end{array}$ & $\begin{array}{c}\text { Infertile }^{2}(\% \text { of } \\
\text { animals) }\end{array}$ & $\begin{array}{c}\text { Resorbed }^{3}(\% \text { of } \\
\text { animals) }\end{array}$ \\
\hline $\begin{array}{c}\text { Control } \\
\text { PB at 12-20 days } \\
\text { of pregnancy }\end{array}$ & $\begin{array}{c}100(8)^{4} \\
58(7)^{5}\end{array}$ & 0 & 0 \\
$\begin{array}{c}\text { PB at 14-20 days } \\
\text { of pregnancy }\end{array}$ & $63(8)^{5}$ & 25 & 28 \\
$\begin{array}{c}\text { PB at 17-20 days } \\
\text { of pregnancy }\end{array}$ & $50(8)^{5}$ & 25 & 12 \\
$\begin{array}{c}\text { PB at 1-8 post- } \\
\text { natal days }\end{array}$ & $50(8)^{5}$ & 33 & 25 \\
\hline
\end{tabular}

' Fertility data are based upon mating for 2 to 5 days until the first appearance of sperm in vagina.

${ }^{2}$ The animals did not conceive.

${ }^{3}$ The animals conceived but resorbed fetuses.

${ }^{4}$ Number in the parentheses indicates the number of animals used for determination.

${ }^{5} P<0.01$.

Table 3. Effect of $P B$ administration during different periods of prenatal and postnatal development upon plasma estrogen and uterine estrogen receptor concentration at adult age

\begin{tabular}{|c|c|c|}
\hline Treatment & $\begin{array}{c}\text { Estradiol-17 } \beta(\mathrm{pgm} / \mathrm{ml} \\
\text { plasma) }\end{array}$ & $\begin{array}{l}\text { Estradiol receptor } \\
\text { (pmole/mg protein) }\end{array}$ \\
\hline Control & $58.5 \pm 12.2(6)^{1}$ & $0.136 \pm 0.026(6)$ \\
\hline $\begin{array}{l}\text { PB at } 12-20 \text { days } \\
\text { of gestation }\end{array}$ & $107.0 \pm 18.1(8)^{2}$ & $0.265 \pm 0.037(8)^{2}$ \\
\hline $\begin{array}{l}\text { PB at } 14-20 \text { days } \\
\text { of gestation }\end{array}$ & $129.5 \pm 38.1(8)^{2}$ & $0.222 \pm 0.026(8)^{2}$ \\
\hline $\begin{array}{l}\mathrm{PB} \text { at } 17-20 \text { days } \\
\text { of gestation }\end{array}$ & $155.2 \pm 25.1(7)^{2}$ & $0.242 \pm 0.031(7)^{2}$ \\
\hline $\begin{array}{l}\text { PB at } 1-8 \text { postnatal } \\
\text { days }\end{array}$ & $268.0 \pm 16.7(7)^{2}$ & $0.202 \pm 0.040(7)^{2}$ \\
\hline
\end{tabular}

were due to the hypnotic-sedative effects of PB with secondary nutritional deficiency or hypoxia.

The suggestion derived from the present results, that PB may act at the brain, is supported by other observations. For example, Middaugh et al. (18) found retarded development of several neurologic reflexes in mice whose mothers received PB in midpregnancy. A defect in sexual mating behavior after neonatal exposure to the drug has been demonstrated by Clemens et al. (3).
These observations further support the concept that the nervous system during the perinatal period is labile and that the fina setting of the neuroendocrine axis may be modified by pharma. cologic agents.

The demonstration that PB administration during pregnancy is capable of interfering with the organization of the neuroendocrine mechanism, indicates its action at the brain. However, the precise mechanism of action is poorly understood. There is some evidence that the perinatal rat pituitary may be involved in organizing the differentiation of the brain as female with subsequent readoul during puberty and adulthood. Sheridan et al. (23) demonstrated that neonatal gonadotrophin is necessary in the development of cyclicity in the rat. Using anti-luteinizing hormone: follicle-stim. ulating hormone, Goldman et al. (8) demonstrated that perinatal treatment with anti-luteinizing hormone: follicle-stimulating hormone did induce long-term effects on pubertal and adult reproductive function in female rats. PB may act upon the hypothalamus to inhibit gonadotrophin release during the perinatal period and by this mechanism may produce reproductive dysfunction. On the other hand, prenatal administration of an inhibitor of 3 . $\beta$-hydroxy steroid dehydrogenase in the biosynthesis of progesterone, was found to delay the onset of puberty and to cause a prolonged estrous cycle (22). PB inhibits the release of progesterone in the adult female $(4,10,11)$. Therefore, prenatal administration of PB may produce a permanent change in neuroendocrine axis by producing a suppressed level of progesterone. Furthet work in these areas is needed to elucidate the precise mechanism of action. This is a necessary prerequisite to interpreting the clinical relevance of these striking and permanent effects of pre. natally administered PB.

\section{REFERENCES AND NOTES}

1. Barraclough, C. A.: Hormones and development. Recent Prog. Horm. Res., 22. 503 (1966).

2. Bruria, F., Nimrod, A., and Lindner, H. R.: The development of steroidogenic capability and responsiveness to gonadontrophins in cultured neonatal ra ovaries. Endocrinology, 106: 98 (1980).

3. Clemens, L. G., Popham, T., and Ruppert, P. H.: Neonatal treatment of hamste with barbiturate alters adult sexual behavior. Dev. Psychobiol., 12: 49 (1979)

4. Everett, J. W.: Neuroendocrine aspects of mammalian reproduction. Ann. Rev. Physiol., 3I: 383 (1969).

5. Feldman, S. C., and Bloch, E.: Developmental pattern of testosterone synthesis by fetal rat testes in response to luteinizing hormone. Endocrinology. 102: 999 (1978).

6. Forest, M. G.. Lecoq, A., Salle, B., and Bertrand, J.: Phenobarbital et axe hypothalamo-hypophysio-testiculaire chez le premature. In: Mathieir. H., Pontonnier, G.. Olive, G.: Colloques INSERM, Vol. 89, pp. 95-104 (INSERM Paris, 1979).

7. Gassano, G. D., Ghetti, B., Gliozzi, E., and Hansson, E.: Auto radiographic distribution study of "short-acting" and "long-acting" barbiturates.: "S-thiopentane and ${ }^{14} \mathrm{C}$ phenbarbitone. Br. J. Anaesth., 39: II (1967).

8. Goldman, A. S., Shapiro, B. H., and Root, A. W.: Inhibition of fetal masculine 
differentiation in the rat by miaternal administration of antibodies to bovine $\mathrm{LH}$, cyanoketone, or antibodies to testosterone-3-bovine serum albumin. Proc. Soc. Exp. Biol. Med., 143: 422 (1973).

9. Gupta. C., and Bloch. E.: Testosterone binding protein in reproductive tracts of fetal rats. Endocrinology, 99: 389 (1976).

10. Gupta, C., and Karavolas, H. J.: Lowered ovarian conversion of ${ }^{14} \mathrm{C}$ pregnenolone to progesterone and other metabolites during phenobarbital block of PMSinduced ovulation in immature rats: inhibition of $3 \beta$-hydroxy steroid dehydrogenase. Endocrinology, 92: 117 (1973).

11. Gupta, C., and Karavolas, H. J.: Adrenal steroid biosynthesis from ${ }^{14} \mathrm{C}$-cholesterol (in vitro) during phenobarbital block of PMS-induced ovulation in immature rats. Endocrinology, 92: 120 (1973).

12. Gupta, C., Sonawane, B. R., Yaffe, S. J., and Shapiro, B. H.: Phenobarbital exposure in utero: Alterations in female reproductive functions in rats. Science 208: 508, (1980).

13. Gupta, C., Shapiro, B. H., and Yaffe, S. J.: Reproductive dysfunction in male rats following prenatal exposure to phenobarbital. Pediatr. Pharmacol., $1: 55$ (1980).

14. Jost, A.: Problems of fetal endocrinology: the gonadal and hypophyseal hormones. Recent Prog. Horm. Res., 8: 379 (1953).

15. Jost, A.: Modalities in the action of androgens on the foetus. Res. Steroids, 3: 207 (1967).

16. Korenman, S. G., Stevens, R. H., Carpenter, L. A., Robb. M., Niswender, G. D. and Sherman, B. M.: Estradiol radioimmunoassay without chromatography: procedure validation and normal values. J. Clin. Endocrinol. Metab., 38: 718 (1974).

17. Maynert, E. W., and Van Dyke, H. K.: The metabolism of barbiturates. Pharmacol. Rev., I: 217 (1949).
18. Middaugh, L. D., Santos, C. A., III, and Zemp. J. W.: Effect of phenobarbital given to pregnant mice on behavior of mature offspring. Dev. Psychobiol., 8 : 305 (1975).

19. Nishizuka, M.: Neuropharmacological study on the induction of hypothalamic masculinization in female mice. Neuroendocrinology, 20: 157 (1976).

20. Price. D., and Ortiz, E.: The role of fetal androgen in sexual differentiation in mammals. In: R. L. De Haan, H. Ursprung: Organogenesis. Chap. 25. pp. 629-652 (Holt Rinhart and Winston, New York, 1965).

21. Quattropani, S. L., and Weisz, J.: Conversion of progesterone to estrone and estradiol in vitro by the ovary of the infantile rat in relation to the development of its interstitial cells. Endocrinology, 93: 1269 (1973).

22. Shapiro, B. H., Goldman, A. S., Bongiovanni, A. M., and Marino. J. M.: Neonatal progesterone and feminine sexual development. Nature, 264: 795 (1976).

23. Sheridan, P. J., Zarrow, M. X., and Denenberg, V. H.: The role of gonadotrophin in the development of cyclicity in the rat. Endocrinology, 92: 500 (1973).

24. Stinnakre, M. G.: Periode de sensibilite aux androgenes du canal de Wolff de foetus de rat. Arch. Anat. Microsc. Morphol. Exp., 64: 45 (1975).

25. Waddell, W. J., and Butler, T. C.: The distribution and excretion of phenobarbital. J. Clin. Invest., 36: 1217 (1957).

26. Weisz, J., and Ward, I. L.: Plasma testosterone and progesterone titers of pregnant rats, their male and female fetuses and neonatal offspring. Endocrinology, 106: 306 (1980).

27. Requests for reprints should be addressed to: Sumner J. Yaffe, M. D., Div. of Clinical Pharmacology, Children's Hospital, One Children`s Center, Philadelphia. PA 19104 (USA).

28. This research was supported by USPHS Grants HD 10063 and T32-GM 07514.

29. Received for publication November $25,1980$.

30. Accepted for publication April 1, 1981 